\title{
Recovery of the Vulnerable Pemba flying fox Pteropus voeltzkowi: population and conservation status
}

\author{
Janine E. Robinson, Diana J. Bell, Fatma M. Saleh \\ AHMED A. SULEIMAN and IAIN BARR
}

\begin{abstract}
Flying foxes of the genus Pteropus are predominantly island taxa, with high levels of endemism, and face high risks of extinction. Their ecological and economic importance in island ecosystems has been widely recognized. Here we investigate the population size and conservation status of the Vulnerable Pteropus voeltzkowi, endemic to the western Indian Ocean island of Pemba, Tanzania. Direct counts and patch counts were used to determine abundance of flying foxes at roost sites, supplemented with evening dispersal counts, which were conducted to test accuracy of counting techniques under varying conditions of visibility. We estimate that the population size is now a minimum of $18,200-22,100$, thus validating reports of annual increases by in-country monitoring teams since the last documented population survey of 4,600-5,500 bats in 1995. Taking into account differences in the counting methodologies for roosting bats we estimate that the population size could be as high as 35,600 individuals. We identified 44 occupied roosting sites, with just four of these supporting up to $87 \%$ of the population. Roost disturbance represents a continuing threat to this species and was found to influence roost occupancy and colony size. The implications of the population increase for the local human community are discussed and recommendations provided for continued monitoring and future management of this species on Pemba Island.
\end{abstract}

Keywords Disturbance, flying fox, fruit bats, Pemba Island, population recovery, Pteropidae, Pteropus voeltzkowi, Tanzania

\section{Introduction}

Clying foxes of the genus Pteropus are predominantly island-based species, with high endemism, and have therefore received significant conservation attention because of their vulnerability and their ecological and eco-

Janine E. Robinson* (Corresponding author), Diana J. Bell and IAIN BARR Centre for Ecology, Evolution and Conservation, University of East Anglia, Norwich, NR4 7TJ, UK. E-mail janine.robinson82@gmail.com

Fatma M. Saleh and Ahmed A. Suleiman Department of Commercial Crops, Fruits and Forestry, Zanzibar, Tanzania

${ }^{*}$ Current address: 30 Atkinson Street, Peterborough, PE1 5HW, UK

Received 25 February 2009. Revision requested 14 April 2009.

Accepted 17 November 2009. nomic importance in island ecosystems (Cox et al., 1991; Fujita \& Tuttle, 1991; Mickleburgh et al., 1992; Shilton et al., 1999). Island endemics typically occupy a small geographic range and have often evolved in isolation from predators and competitors, making them vulnerable to the effects of overexploitation and introduced species (Purvis et al., 2000; Jones et al., 2003). Flying foxes usually roost in large social groups, increasing their vulnerability to human hunting, and have low reproductive rates (Pimm et al., 1988; Jones et al., 2003). Major threats to flying foxes include habitat loss or modification, roost site loss or disturbance, and disease (Mickleburgh et al., 1992; Daszak et al., 2004). In addition to this, flying fox meat is often consumed by humans, which can lead to subsistence hunting (Craig et al., 1994a) and overexploitation for commercial trade (Brautigam \& Elmqvist, 1990; Struebig et al., 2007; Mickleburgh et al., 2009). Threats are exacerbated on islands, where human populations are increasing rapidly, habitat is limited and additional events such as cyclones can have devastating consequences (Craig et al., 1994b; Pierson et al., 1996; Mickleburgh et al., 2002).

The Pemba flying fox Pteropus voeltzkowi is endemic to the Indian Ocean island of Pemba, Tanzania. Although described as numerous in the 1940 s, a 1989 study reported a dramatic population decline despite searching previously common roost sites (Seehausen, 1991). Subsequent surveys in the early 1990s revealed that the species' status was not as critical as earlier thought but it was evident that $P$. voeltzkowi and its habitat had undergone significant declines (Entwistle \& Corp, 1997b; O. Seehausen, unpubl. data). These studies indicated that the species was at risk of extinction as a result of hunting and habitat loss, and it was categorized as Critically Endangered on the IUCN Red List in 1996 (Seehausen, 1991; Mickleburgh et al., 2008).

Conservation activities were initiated in 1992, with a school education programme focused on seed dispersal and forest regeneration (O. Seehausen, unpubl. data). In 1995 additional education programmes built on this work, in combination with population and ecological studies (Entwistle \& Corp, 1997b,c). Since 1997 the project has been conducted by the Department of Commercial Crops, Fruit \& Forestry (DCCFF) on Pemba, with continued support from Fauna \& Flora International (FFI). Interdisciplinary conservation activities include raising public awareness and outreach through village meetings and schools, seminars with community leaders, production of 
educational videos and provision of small grants for village environmental projects (Entwistle, 2001a). Community conservation clubs were established to protect and monitor roosts in villages and the public were educated on the impacts of continued hunting (Trewhella et al., 2005). A detailed population survey conducted in 1995 reported a minimum of 4,600-5,500 bats (Entwistle \& Corp, 1997b). Successive in-country monitoring by DCCFF indicated that the population continued to show a steady recovery. The population had increased to 6,900 by the year 2001 and $>11,000$ in 2005 (Entwistle, 2001a; Carter, 2005). The species' Red List status was subsequently downgraded from Critically Endangered to Vulnerable in 2004 (Mickleburgh et al., 2008), and it is also listed on CITES Appendix II (CITES, 2009).

Nevertheless, $P$. voeltzkowi faces continuing threats to its long-term conservation. Pemba Island has a high human population density of c. $501 \mathrm{~km}^{-2}$ and habitat degradation and clearing of land for agriculture continue, leading to loss of roost sites and feeding areas and to roost disturbance. Hunting is also thought to be one of the drivers of population decline in this species (Entwistle, 2001b), with techniques changing from traditional harvesting to the use of modern weapons, including shotguns (Seehausen, 1991). In addition, $P$. voeltzkowi is known to feed on both cultivated and forest fruits (Entwistle \& Corp, 1997c) and a population increase could potentially lead to conflict with local fruit growers.

We investigated the population size and conservation status of $P$. voeltzkowi $>15$ years after conservation efforts began, and validated methodologies and the results of incountry monitoring since 1995 . We aimed to obtain an accurate population estimate for $P$. voeltzkowi, investigate its distribution and assess current threats to future population growth. We compare the past and present status of the population, and present recommendations for future in situ conservation efforts and population monitoring.

\section{Study area}

The $980 \mathrm{~km}^{2}$ Pemba Island (Fig. 1), in the western Indian Ocean $50 \mathrm{~km}$ off the coast of mainland Tanzania, forms part of the Zanzibar archipelago. Historically the western side of the island was covered in tropical rainforest whereas the eastern half was dominated by baobab Adansonia digitata and borassus (Palmae) palm savannahs and coastal bush (Seehausen, 1991). Much of Pemba's original forest was cleared in the 18th century for clove Syzygium aromaticum plantations, which have since been largely abandoned and replaced by secondary growth forest (Entwistle \& Corp, 1997c). Continuing deforestation and the use of slash-andburn agriculture mean that the secondary forest is also under threat from increasing human pressure, and only remnants of native forest remain.

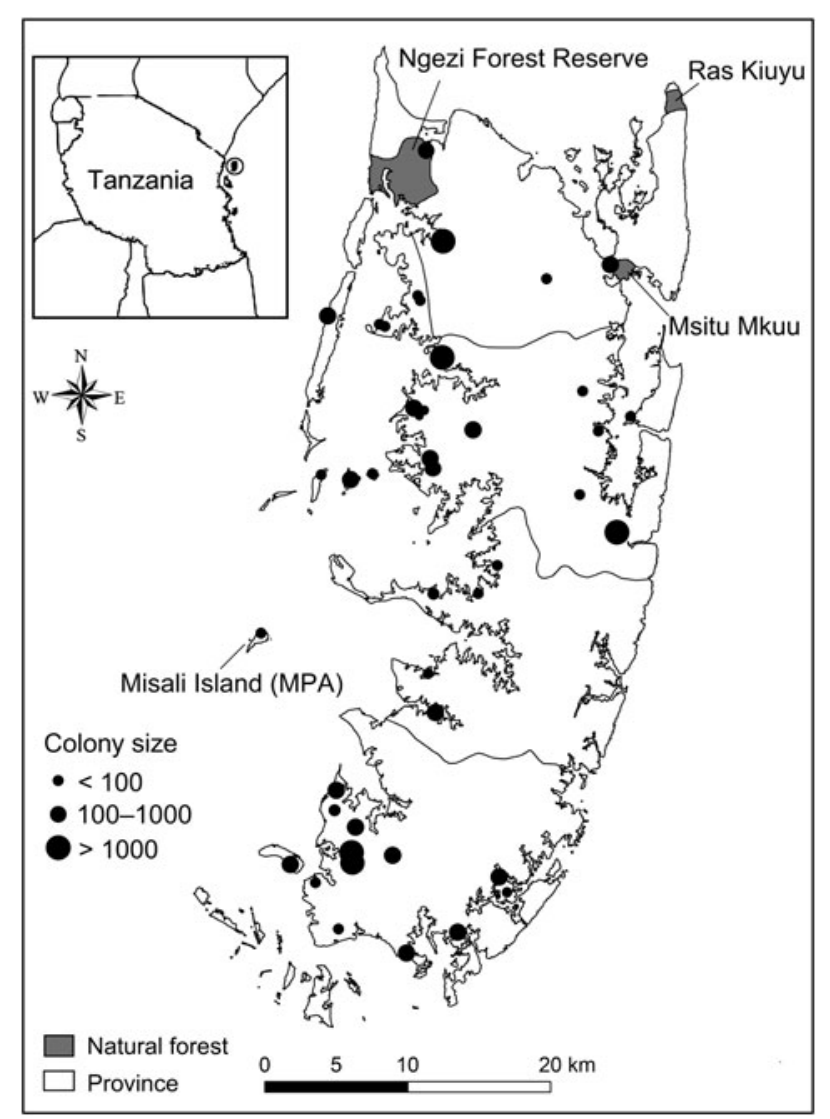

Fig. 1 The distribution of all occupied Pemba flying fox Pteropus voeltzkowi roosts on Pemba Island, Tanzania. Circle on inset indicates the position of Pemba and neighbouring islands within the Zanzibar archipelago off the east coast of Tanzania.

\section{Methods}

Roost sites were located using records from previous surveys and from local knowledge. Survey teams consisted of three individuals, and villagers were often recruited as guides. Roost counts were conducted between 23 March and 23 May 2008. During this time two complete counts were conducted of all known roost sites. To minimize error because of any movement of bats between roosts, surveys were completed in as short a time as possible and adjacent roosts surveyed on the same day. Performing two complete roost counts helped to establish the degree of confidence in detectability and numbers of $P$. voeltzkowi at roost sites. However, because the second complete count was made in less time we have greater confidence in its findings. Statistics were applied to both surveys to ensure an unbiased analysis.

Data were collected on roost vegetation structure and other habitat variables at each roost site. We recorded tree species, diameter at breast height, and canopy cover for all main roost trees. Site type (primary forest, secondary forest, graveyard, mangrove or isolated tree) was recorded based on gross habitat structure and habitat use characteristics.

Colony counts followed methodologies used in the previous population survey by Entwistle \& Corp (1997b) and by 
in-country teams, to enable direct comparison of results. We used two counting methods; direct counts and patch counts (Thomas \& LaVal, 1988). Direct counts involved counting all bats in the roosting area. Patch counts, however, were conducted when visibility was low, in which case one or more patches were counted and then extrapolated to provide an estimate of the entire roost based on the percentage encompassed by the patch(es) counted. The mean of three independent observers' counts were used.

To test the accuracy of patch counts a more detailed assessment of colony size was made at nine roosts of varying sizes and with varying visibility. Evening dispersal counts were carried out on the same day as patch counts, to compare and validate the results. Roost visibility was graded as low (dense foliage or large number of bats), medium (reasonable view of bats but some clustering or bats hidden from view) or high (bats clearly visible). Departures of bats were recorded as they left the roost, from half an hour before sunset until no further bats were observed leaving the roost for a 30 -minute period or it was too dark to observe them.

Geographical information system (GIS) layers and Landsat imagery (2005) were obtained from DCCFF, Zanzibar. Global positioning system (GPS) data were taken for each roost and incorporated into a GIS layer in ArcMap v. 9.2 (ESRI, Redlands, USA) and used to create a distribution map. Between roost distances, for active colonies, were calculated using the GIS. The areas of 10 forest fragments containing roosts were calculated using a combination of the GPS and GIS.

Threats were assessed directly by investigating effects of human disturbance on roost sites (felling, burning) and searching for evidence of hunting (snares, shotgun cartridges), and indirectly by semi-structured interviews. Two measures of disturbance were used: disturbance was graded as low, medium or high based on the amount of direct disturbance at the site, and the distance of roosts to human settlements was determined. Proximity to settlement $(>10$ aggregated houses) was calculated by incorporating GPS data for villages into a GIS layer.

Semi-structured interviews were conducted with a total of 66 people (including conservation club members, school children and general community members), from 44 villages surrounding roosts.

To investigate differences in colony size between major habitat types we compared paired counts from each roost and differences in the habitat between sites, incorporating the counts made in the two surveys, using repeated measures ANOVA. Roosts within $500 \mathrm{~m}$ of each other and/or where it was confirmed that bats were moving between them were combined as one roost for analysis. All roosts outside major towns were included in the analyses, excluding roosts on small offshore islands, as isolation may influence distribution and behaviour. One roost site (Msitu mkuu) was removed as an outlier from the first survey as we suspected it to be a small part of a larger colony.

To investigate effects of disturbance and human proximity on roost occupancy, binary logistic regression analysis was used. As this survey was not designed to produce an accurate predictive model of species presence, these models were mainly built to indicate whether disturbance and other variables may be related to roost distribution. A general linear model was subsequently used to investigate these effects on colony size at occupied roosts. Disturbance and distance to nearest settlement were added as covariate predictors. In the binary logistic regression and the general linear model habitat type and distance from nearest neighbouring active roost were added to the model as additional predictors of occupancy or colony size.

\section{Results}

The total number of bats counted in the first and second surveys were 18,188 and 22,116, respectively. The mean colony sizes of roosts are provided in Table 1 . Roosts ranged from solitary individuals to colonies of up to 5,040 bats.

TABle 1 The total number of roost sites occupied by the Pemba flying fox Pteropus voeltzkowi (n), mean \pm SE, and range of colony sizes within each habitat type, for both surveys. Roosts were located in trees in primary forest (protected forest reserves and offshore islands), secondary forest (often overgrown clove plantations), village graveyards (pockets of native or well-developed secondary vegetation, protected by religious taboo), isolated trees (often mango Mangifera indica trees within villages) and mangroves.

\begin{tabular}{|c|c|c|c|c|c|c|}
\hline \multirow[b]{2}{*}{ Site type } & \multicolumn{3}{|c|}{ Survey 1} & \multicolumn{3}{|c|}{ Survey 2} \\
\hline & $\mathrm{n}$ & Mean \pm SE & Range & $\mathrm{n}$ & Mean \pm SE & Range \\
\hline Primary & 4 & $41 \pm 25.6$ & $5-117$ & 5 & $315 \pm 155.0$ & $15-834$ \\
\hline Secondary & 11 & $114 \pm 568.7$ & $1-4,819$ & 13 & $983 \pm 442.7$ & $3-5,040$ \\
\hline Graveyard & 14 & $322 \pm 238.7$ & $3-3,394$ & 16 & $441 \pm 306.4$ & $1-4,978$ \\
\hline Graveyard excluding Kidike & 13 & $85.73 \pm 36.5$ & $3-465$ & 15 & $138.8 \pm 53.0$ & $1-633$ \\
\hline Mangrove & 1 & 88 & & 2 & $109 \pm 43.5$ & $65-152$ \\
\hline Isolated tree & 4 & $23 \pm 17.45$ & $3-75$ & 4 & $120 \pm 58.5$ & $31-290$ \\
\hline Total (occupied) & 34 & $510 \pm 217$ & $1-4,819$ & 40 & $553 \pm 192$ & $1-5,040$ \\
\hline Total (visited) & 64 & & & 65 & & \\
\hline
\end{tabular}


A large proportion of the population was found in just a few roosts, with $87 \%$ of the population in four roosts in the first survey and $75 \%$ in five roosts in the second.

Evening dispersal departure rates were highest 0-20 minutes after sunset, and by 30 minutes most bats had left the roost. Patch counts consistently produced lower colony counts than evening dispersal counts at all sites with low visibility, with the exception of one roost (Table 2). The average proportional difference between patch counts and evening dispersal counts, calculated from all roosts with low visibility was 2.43 . This difference was used as a correction factor and applied to all low visibility roosts $(n=25)$, giving a maximum population estimate of 35,631 .

Seventy roost sites were identified, of which 44 were occupied during the course of the surveys. Site types for roosting remain largely unchanged from previous studies and are summarized in Table 1. Although the largest colonies were found in secondary forest or graveyards (primarily one actively protected graveyard), there was no significant difference in colony size between habitat types (repeated measures ANOVA $F_{4,25}=0.74, \mathrm{P}=0.57$ ).

A total of 28 tree species were identified as being utilized for roosting. The most commonly used tree species was Erythrophloeum suaveolens (28\% of records). Mango Mangifera indica (11\%), Terminalia catappa (7\%) and fig Ficus lutes $(7 \%)$ were also commonly used. Roost trees were generally large emergents and estimates of canopy cover of roost trees ranged from 15-99\% (mean $74.15 \pm$ SE 2.58).

Roost sites were widely distributed throughout the island (Fig. 1), as well as on small offshore islands up to $5.9 \mathrm{~km}$ from the coast. The furthest offshore was Misali Island, a Marine Conservation Area. More roosts were located on the west $(n=35)$ of Pemba than the east $(n=9)$. The size of the forest patch in which roosts were located ranged from isolated trees to the intact Ngezi Forest Reserve $(2,900 \mathrm{ha})$. Graveyards (40\% of roosts) were $0.76-2.58$ ha in size (mean $1.34 \pm$ SE 0.19 ha).

Active roosts were $0-1,793 \mathrm{~m}$ from the nearest human settlement (mean 409.63 \pm SE $80.63 \mathrm{~m}$ ). There were significant differences in proximity to settlement between roost types. For example, roosts in primary forest tended to be further from settlements than graveyard roosts and roosts in isolated trees, which were generally adjacent to, or within, villages.

Disturbance was the only significant predictor of presence or absence of colonies at roost sites (Survey 1: binary logistic regression, Wald $=7.60, \mathrm{df}=1, \mathrm{P}<0.01,75.6 \%$ data points classified correctly; Survey 2: binary logistic regression, Wald $=5.21, \mathrm{df}=1, \mathrm{P}<0.05,70.2 \%$ data points classified correctly).

Given the presence of $P$. voeltzkowi at a roost site, disturbance (Survey 1: $F_{1,19}=7.94, \mathrm{P}<0.05$; Survey 2: $F_{1,26}=5.58, \mathrm{P}<0.05$, Fig. 2) and distance to nearest settlement (Survey 1: $F_{1,19}=8.44, \mathrm{P}<0.01$; Survey 2: $F_{1,26}=$ 8.62, $\mathrm{P}<0.01$, Fig. 3) were found to have a significant effect on colony size, with larger colonies occurring at greater distances from settlements and in sites of lowest disturbance.

Results of semi-structured interviews revealed that hunting of $P$. voeltzkowi continues to occur at fairly low levels, for local consumption. Seventy percent $(n=66)$ of interviewees had, or knew someone who had, killed P. voeltzkowi, $93 \%(\mathrm{n}=46)$ of whom stated that they were killed for food, particularly soup. Seventy-nine percent $(\mathrm{n}=66)$ had, or knew someone who had, eaten $P$. voeltzkowi meat, $48 \%(n=33)$ of whom said that this was within the last 5 years. All 66 interviewees stated that the meat is not traded in markets.

\section{Discussion}

The results of this research indicate that the population of P. voeltzkowi has increased substantially since the 1995 survey (Entwistle \& Corp, 1997b), with individual colonies now reaching up to 5,040 bats. This is consistent with the results from annual in-country monitoring that have demonstrated a gradual year-on-year population increase. Our results thus reinforce the findings of the in-country

TABLE 2 Colony counts at nine P. voeltzkowi roost sites, using patch count and evening dispersal count (EDC) methodologies on the same day. Low visibility sites were used to calculate the mean proportional difference.

\begin{tabular}{llrrr}
\hline Roost site & Visibility & Patch count & EDC & Proportional difference \\
\hline Wete port & Low & 3,465 & 6,729 & 1.94 \\
Kidike & High & 4,711 & 2,657 & 0.56 \\
Msitu mkuu & Low & 195 & 812 & 4.16 \\
Mbiji I & Medium & 1,300 & 1,289 & 0.99 \\
Mchanga wa kwale & Low & 7 & 18 & 2.57 \\
Ngezi Forest Reserve & Low & 834 & 1,428 & 1.71 \\
Kiuyu minungwini & Low & 290 & 594 & 2.05 \\
Kiwani mchanga mdogo & Low & 220 & 922 & 4.19 \\
Makombeni II & Low & 630 & 264 & 0.42 \\
Mean proportional difference & & & & 2.43 \\
$\quad$ low visibility roosts only) & & & & \\
\hline
\end{tabular}




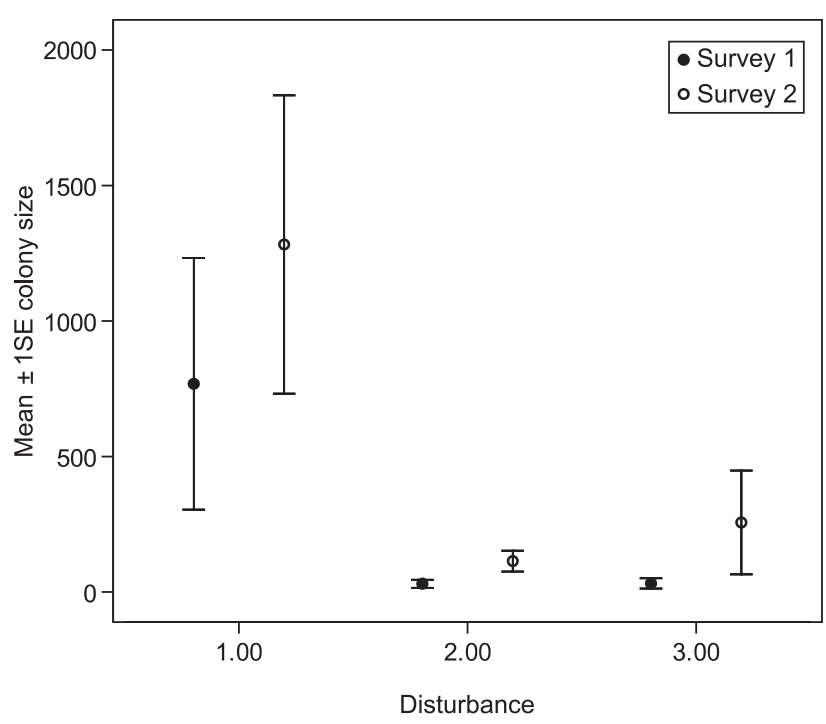

FIg. 2 Effect of disturbance on P. voeltzkowi colony sizes, with disturbance graded for each roost on both surveys. 1, low disturbance; 2 , medium disturbance; 3 , high disturbance.

conservation team and highlight the success of the conservation initiative.

Roosts were widely distributed throughout the island and appeared to occur in pockets of native or well-developed secondary vegetation within a fragmented landscape. Bats were affected by human disturbance, with disturbance at the roost sites emerging as a significant factor affecting occupancy and colony size, and proximity to the nearest human settlement also negatively influencing abundance.

\section{Population recovery}

The total population of $P$. voeltzkowi counted during this survey was 18,200-22,100, an increase of c. 400\% since 1995.

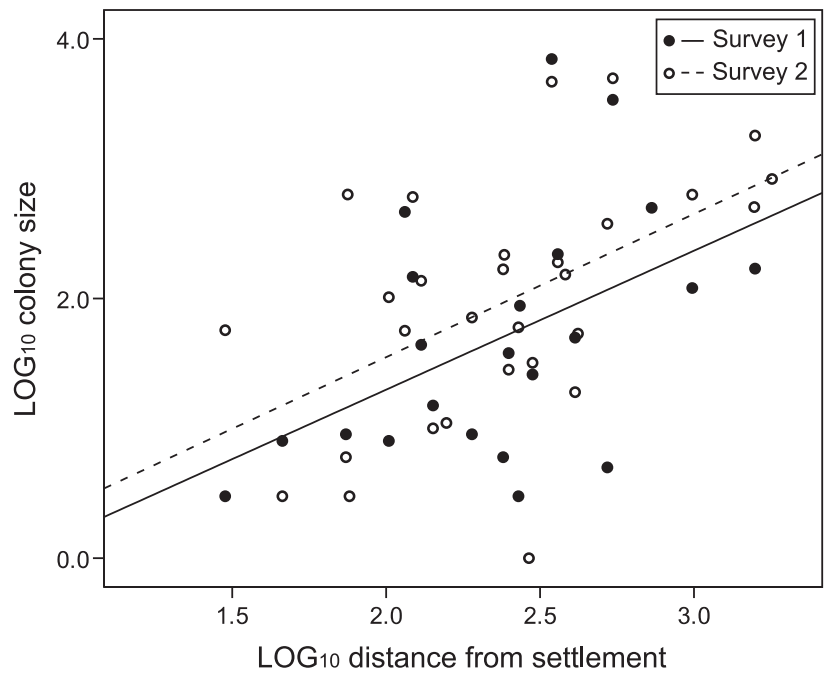

FIG. 3 Relationship between $P$. voeltzkowi colony size and distance from nearest settlement for Surveys 1 and 2. Survey 1 $\left(\mathrm{Y}=1.07 \mathrm{x}-0.84, R^{2}=0.24, \mathrm{n}=22, \mathrm{P}<0.05\right)$; Survey 2 $\left(\mathrm{Y}=1.10 \mathrm{x}-0.66, R^{2}=0.28, \mathrm{n}=29, \mathrm{P}<0.001\right)$.
This expansion is apparent both in the increase in number of roosts and the numbers of bats within individual roosts (Table 3) and we found at least three substantial new roosts ( $>100$ bats) not recorded in previous years. Whilst it is possible that some roost sites remain undiscovered it is unlikely that any permanent or substantial colonies could have gone undetected because of the detailed knowledge of the species amongst villagers and the expanse of human habitation. However, it is possible that some temporary roosts, or roosts in inaccessible areas, were not located during our surveys and hence the population estimate should be considered a minimum size. Additionally, this study shows that conventional counting methods may underestimate numbers and, as discussed below, the true population figure could be substantially greater.

Community protection at specific roosts is thought to be the primary factor determining the increase of bats at those sites (Entwistle, 2001a). We found a large proportion (up to $87 \%$ ) of the population at just four roost sites (Kidike, Mbiji I, Mbiji II and Wete) of which three have been protected, to varying degrees, by local conservation clubs through the DCCFF/FFI conservation programme. Kidike graveyard roost has been actively protected by a village conservation club for at least 10 years. The club regularly monitors the bats, prohibits harvesting of timber at the roost and ensures disturbance is minimized. They also have a visitor centre and nature trail and the production of leaflets and road signs facilitate tourism and raise awareness. In 1995, 855 $P$. voeltzkowi were counted compared to our estimate of up to 5,000, and there is evidence of the bats expanding out of the graveyard into neighbouring trees. Mbiji roost formed in 2004 and has now expanded from one to two roosts, hosting up to 7,00o bats; Mbiji I and II are close to each other in secondary forest patches and have also been protected by conservation club members in the local village since 2005, but to a lesser extent than Kidike. Club members patrol the colonies and minimize disturbance to the roosts. Wete is

TABLE 3 Comparison of the results of $P$. voeltzkowi roost surveys in 1995 (Entwistle \& Corp, 1997b) and the 2008 survey.

\begin{tabular}{lll}
\hline & 1995 & 2008 \\
\hline Total population & $4,600-5,500$ & $18,200-22,100$ \\
$\begin{array}{l}\text { Total number of roost } \\
\quad \text { sites visited }\end{array}$ & 41 & 70 \\
$\begin{array}{l}\text { Total number of occupied } \\
\quad \text { roosts }\end{array}$ & 19 & 44 \\
Roosts $<100$ & 9 & \\
Roosts $100-999$ & 10 & 20 \\
Roosts $1,000-1,999$ & 0 & 19 \\
Roosts $2,000-4,999$ & 0 & 1 \\
Roosts $\geq 5,000$ & 0 & 3 \\
\end{tabular}

${ }^{*}$ Includes all roosts previously known to be occupied by $P$. voeltzkowi and previously unknown roosts identified using local knowledge 
a large roost site at the port of one of Pemba's largest towns and does not receive any active protection. It formed in 2006 and now holds up to 5,040 bats.

The abundance of bats in these four sites is probably due to local environmental conditions and plentiful food resources, with protection a contributing factor for the Mbiji and Kidike roosts. As well as direct protection the conservation programme has also worked to reduce hunting of $P$. voeltzkowi through education and awareness and a ban on hunting with guns, along with promoting an increased general environmental awareness. These factors probably explain why the species is thriving at sites without direct protection (such as the Wete roost), as may increased food abundance, changes in patterns of illegal felling and reduced disturbance of roosts in forest areas.

Another factor that may have contributed to the population recovery is land-use change, particularly the abandonment of clove plantations and subsequent changes in vegetation. Clove production has decreased since the 1960 s and plantations abandoned recently now hold $P$. voeltzkowi. However, without quantitative information on land-use changes it is difficult to ascertain the extent to which this may have influenced the recovery. The presence of $P$. voeltzkowi in overgrown clove plantations and bats feeding on mature clove fruits, witnessed during this study, along with the fact that they eat both wild and cultivated fruit (Entwistle, 1997a), demonstrates the species' adaptability and this may have helped them survive during a reduction in their native food plants.

\section{Effect of census technique}

The accuracy of patch counts at low visibility roosts is a problem on Pemba as roosts are commonly located in trees with dense foliage. During evening dispersal counts bats often emerged from nearby trees not recorded to contain bats during the diurnal surveys. Other surveys in American Samoa and Madagascar have reported similar discrepancies between daytime counts and evening dispersal counts (Grant, 1998; Jenkins et al., 2007). Such count inaccuracies have implications for monitoring. Our study highlights the effectiveness of evening dispersal counts to obtain accurate colony counts in areas of low visibility. The inaccuracies of patch counts become more prevalent as the population increases and more roosts must be counted in this way. Where it is not possible to carry out evening dispersal counts (because of limited resources, for example), a comparison between methods may improve the accuracy of daytime patch count estimates. The survey at Makombeni, where the evening dispersal count did not give an estimate higher than the patch count, was carried out during a full moon, which has been shown to influence departure rates of fruit bats (Morrison, 1980; Singaravelan \& Marimuthu, 2002). An abundance of ripe fruit within the graveyard may also have encouraged bats to forage around the roost site rather than depart on that particular evening.

\section{Roost characteristics}

P. voeltzkowi continues to show a preference for forest, with colonies mostly found in primary, secondary or graveyard forest patches. Secondary forest patches and graveyards represent pockets of refuge habitat within a fragmented and disturbed landscape. Graveyard patches are protected by religious taboo and thus seem to provide important refugia, accounting for c. $40 \%$ of roosts.

There has been little change in preferred roost tree species since the 1995 survey, with E. suaveolens remaining the most commonly used species. $P$. voeltzkowi also continues to show preference for tall emergent trees and thick foliage, which may offer protection from predation (Mickleburgh et al., 1992). In Ngezi Forest and Kidike, however, bats were roosting on denuded, exposed branches. Both of these roosts are protected (Ngezi is a protected area) and Ngezi is also a considerable distance from the nearest human settlement. The high level of protection and isolation at these sites may mean that concealment by dense foliage is less important. In addition to this, any roosts in isolated trees within villages often received local protection from the community that allowed them to persist. These observations suggest that the bats' behaviour and persistence at roost sites is influenced by human disturbance.

\section{Disturbance}

Human disturbance appears to present a major threat to $P$. voeltzkowi. Not only does disturbance at a roost site have a significant negative effect on colony size, it also influences distribution, roost characteristics and behaviour. Proximity to settlement represents another measure of potential human influence and also has a significant negative effect on colony size. This is to be expected as roosts close to human settlements are at increased risk of disturbance and hunting, which may in turn affect survival or reproductive success.

The relationship between colony size and level of disturbance does not appear to be linear, with some large colonies appearing to withstand high levels of disturbance. Differences in the behavioural response of bats to disturbance were also observed, with individuals in some sites taking flight at the first sign of human approach whereas at others it was possible for observers to stand directly under the roost without the bats showing any signs of alarm. It is likely that the presence and size of colonies is determined by a cost-benefit analysis of a number of factors. Gill et al. (2001) suggested that the decision whether or not to move away from disturbed areas will be determined by factors such as the quality of the site being occupied, distance to other quality sites, relative risk of predation, density of 
competitors, or the investment the individual has made in the site.

\section{Other threats}

Expanding flying fox populations are increasingly likely to come into contact with people, particularly as human populations also expand. This can lead to increased instances of conflict between bats and people, such as has been observed with Pteropus niger on Mauritius, where at least one species, Pteropus subniger, has already gone extinct (Carroll \& Feistner, 1996). Interviews with villagers revealed some instances of conflict between farmers and fruit bats on Pemba but it has not been ascertained whether this is at levels that harm livelihoods, and many of these people considered that the bats are not causing as much damage as the Pemba vervet monkey Cercopithecus aethiops nesiotes and bushbabies Galago spp., or only causing minimal damage. Methods of killing $P$. voeltzkowi included the use of snares and catapults, and methods of scaring bats away included use of scarecrows, tins on strings and the throwing of stones and sticks.

\section{Conclusions}

Conservation initiatives on Pemba have supported the recovery of $P$. voeltzkowi and interviews with community members revealed a positive attitude towards the species. Active protection at roost sites and raising community awareness are likely to have been the primary factors in promoting the population increase. Additional factors, such as the abandonment of clove plantations and subsequent changes in vegetation may also have contributed to the population recovery. Although the population size of $P$. voeltzkowi has increased considerably since the 1995 survey, disturbance of roost sites continues.

With such a large proportion of the population occurring at just a few roosts it is important that protection is maintained at current levels or increased at more vulnerable sites. Other sites that should be considered for prioritized protection include those that have been in long-term use by the bats. Of the 19 roost areas occupied in the 1995 survey we found 12 to be still occupied. Earlier literature described roosts as occurring on islands off the south and west of Pemba and two sites presently occupied (Kichunjuu and Kiwani) were described by Packman (1984) as being 'frequently used' in 1945 (cited in Entwistle \& Corp, 1997a). This suggests $P$. voeltzkowi uses traditional roost sites, with at least two sites being occupied for $>53$ years.

Future considerations should include the close monitoring of levels of conflict between bats and fruit farmers, and a system of reporting and possible mitigation measures (such as nets over trees) investigated for potential integration into the long-term conservation management plan. Alternative, income-generating development projects and ecotourism initiatives may benefit communities and help support the conservation of $P$. voeltzkowi. Although there were reports of disease among the bats causing mortality, there has been no research into the pathogens that this species may be carrying. Bat-borne pathogens, such as Hendra and Nipah virus, can influence both bat and human health (Halpin et al., 1999; Daszak et al., 2004).

Ongoing monitoring and regular programme evaluation is an essential aspect of conservation projects. Important lessons can be learned from successful projects that can be integrated into conservation programmes elsewhere. Our study reports a large population increase following at least 15 years of conservation of $P$. voeltzkowi, validates results of in-county monitoring, and also demonstrates that as population status changes so may conservation management requirements.

\section{Acknowledgements}

This study was carried out in conjunction with the DCCFF in Tanzania: in particular we would like to thank S.J. Ali, Dr B.S. Asseid, K.H. Madeweya and A.J. Mzee for their hospitality, logistical support and advice. Special thanks are also due to B. Liggitt and J. Juma (FFI), Dr R. Lamprey, Dr J. Gill, E. Carter, C. Farese and J. Bicknell. Financial support was provided by the School of Biological Sciences at the University of East Anglia, FFI, the Zoological Society of London and the Sir Phillip Reckitt Educational Trust.

\section{References}

Brautigam, A. \& Elmqvist, T. (1990) Conserving Pacific Island flying foxes. Oryx, 24, 81-89.

Carroll, J.B. \& Feistner, A.T.C. (1996) Conservation of Western Indian Ocean fruit bats. Biogeographie de Madagascar, 1996, 329-335.

Carter, E. (2005) Sub-Report III. Unpublished Report. The Pemba Flying Fox Conservation Project, Cambridge, UK.

CITES (2009) The CITES Appendices. Http://www.cites.org/eng/app/ index.shtml [accessed 2 August 2009].

Cox, P.A., Elmquist, T., Pierson, E.D. \& Rainey, W.E. (1991) Flying foxes as strong interactors in south pacific island ecosystems: a conservation hypothesis. Conservation Biology, 5, 448-453.

Craig, P., Morrel, T.E. \& So'oto, K. (1994a) Subsistence harvest of birds, fruit bats, and other game in American Samoa, 19901991. Pacific Science, 48, 344-352.

Craig, P., Trail, P. \& Morrel, T.E. (1994b) The decline of fruit bats in American Samoa due to hurricanes and over hunting. Biological Conservation, 69, 261-266.

Daszak, P., Tabor, G.M., Kilpatrick, A.M., Epstein, J. \& PlowWright, R. (2004) Conservation medicine and a new agenda for emerging diseases. Annals of the New York Academy of Science, 1026, 1-11.

Entwist Le, A.C. (2001a) Community based protection successful for the Pemba flying fox. Oryx, 35, 355-356.

Entwistle, A.C. (2001b) Bats in a stew: the Pemba flying fox. The IUCN Bulletin, World Conservation, 3, 11. 
ENTwist Le, A.C. \& Corp, N. (1997a) Status and Conservation of the Pemba Flying Fox. Unpublished Report. Aberdeen University, Aberdeen, UK.

Entwistle, A.C. \& Corp, N. (1997b) Status and distribution of the Pemba flying fox. Oryx, 31, 135-142.

Entwistle, A.C. \& Corp, N. (1997c) The diet of Pteropus voeltzkowi, an endangered fruit bat endemic to Pemba Island, Tanzania. African Journal of Ecology, 35, 351-360.

Fujita, M.S. \& Tuttle, M.D. (1991) Flying foxes (Chiroptera: Pteropodidae): threatened animals of key ecological and economic importance. Conservation Biology, 5, 455-463.

Gill, J.A., Norris, K. \& Sutherland, W.J. (2001) Why behavioural responses may not reflect the population consequences of human disturbance. Biological Conservation, 97, 265-268.

Grant, G.S. (1998) Population Status of Pteropus tonganus in Tonga. Atoll Research Bulletin no. 454. National Museum of Natural History, Smithsonian Institution, Washington, DC, USA.

Halpin, K., Young, P.L., Field, H. \& Mackenzie, J.S. (1999) Newly discovered viruses of flying foxes. Veterinary Microbiology, $68,83-87$.

Jenkins, R.K.B., Racey, P.A., Andriafidison, D., Razafindraкотo, N., Razafimahatratra, E., Rabearivelo, A. et al. (2007) Not rare, but threatened: the endemic Madagascar flying fox Pteropus rufus in a fragmented landscape. Oryx, 41, 263-271.

Jones, K.E., Purvis, A. \& Gittleman, J.L. (2003) Biological correlates of extinction risk in bats. The America Naturalist, 161, 601-614.

Mickleburgh, S., Hutson, A.M., Bergmans, W. \& Howell, K. (2008) Pteropus voeltzkowi. In IUCN Red List of Threatened Species v. 2009.1. Http://www.iucnredlist.org [accessed 2 August 2009].

Mickleburgh, S.P., Hutson, A.M. \& Racey, P.A. (1992) Old World Fruit Bats. An Action Plan for their Conservation. IUCN, Gland, Switzerland and Cambridge, UK.

Mickleburgh, S.P., Hutson, A.M. \& Racey, P.A. (2002) A review of the global conservation status of bats. Oryx, 36, 18-34.

Mickleburgh, S., Waylen, K. \& Racey, P. (2009) Bats as bushmeat: a global review. Oryx, 43, 217-234.

Morrison, D.W. (1980) Foraging and day-roosting dynamics of canopy fruit bats in Panama. Journal of Mammalogy, 61, 20-29.

Pierson, E.D., Elmqvist, T., Rainey, W.E. \& Cox, P.A. (1996) Effects of cyclonic storms on flying fox populations on the South Pacific islands of Samoa. Conservation Biology, 10, 438-451.

Pimm, S.L., Jones, H.L. \& Diamond, J. (1988) On the risk of extinction. The American Naturalist, 132, 757-785.
Purvis, A., Gittleman, J.L., Cowlishaw, G. \& Mace, G.M. (2000) Predicting extinction risk in declining species. Proceedings of the Royal Society of London, 267, 1947-1952.

Seemausen, O. (1991) The Pemba fruit bat-on the edge of extinction? Oryx, 25, 110-112.

Shilton, L.A., Altringham, J.D., Compton, S.G. \& Whittaker, R.J. (1999) Old world fruit bats can be long-distance seed dispersers through extended retention of viable seeds in the gut. Proceedings of the Royal Society of London, 266, 219-223.

Singaravelan, N. \& Marimuthu, G. (2002) Moonlight inhibits and lunar eclipse enhances foraging activity of fruit bats in an orchard. Current Science, 82, 1020-1022.

Struebig, M.J., Harrison, M.E., Cheyne, S.M. \& Limin, S.H. (2007) Intensive hunting of large flying foxes Pteropus vampyrus natunae in Central Kalimantan, Indonesian Borneo. Oryx, 41, 390-393.

Thomas, D.W. \& LaVAL, R.K. (1988) Survey and census methods. In Ecological and Behavioural Methods for the Study of Bats (ed. T.H. Kunz), pp. 77-89. Smithsonian Press, Washington, DC, USA.

Trewhella, W.J., Rodriguez-Clark, K.M., Corp, N., Entwistle, A., Garrett, S.R.T., Granek, E. et al. (2005) Environmental education as a component of multidisciplinary conservation programs: lessons from conservation initiatives for critically endangered fruit bats in the western Indian Ocean. Conservation Biology, 19, 75-85.

\section{Biographical sketches}

JANINE ROBINSON is a conservation biologist with a particular passion for Chiropteran ecology. Her interests include zoological research alongside community-based conservation and capacity building. DiANA BELL's current research interests include the impact of wildlife diseases and wildlife trade on biodiversity and ecosystem restoration, particularly on oceanic islands. FA TMA SALEH is a wildlife conservation manager, working with DCCFF Pemba. Fatma plays an active role in environmental education, community-based conservation and enhancing women's participation in the environment. Ahmed Suleiman is a field monitoring officer for DCCFF Pemba and is also an enforcement officer working to reduce illegal harvesting of forest resources. IAIN BARR is an ecologist at UEA with interests in conservation biology and molecular ecology. 